\title{
Water balance regulated by a cloud-based automatic drip fertigation system in bell pepper grown soil
}

\begin{abstract}
Since a fertile top soil in Fukushima, Japan was contaminated with radiocesium due to the nuclear power plant accident occurred in 2011, the fertile top soil was stripped off and replaced by a less fertile sandy soil as a decontaminating process. We applied a cloud-based drip fertigation system, called ZeRo. agri, to grow bell pepper in the less fertile soil in a greenhouse. The Penma-Monteith equation was used to estimate potential evapotranspiration (ET), and time domain reflectometry (TDR) probes were used to measure two-dimensional soil water distribution. The amount of excess water in soil gradually became smaller as time proceeded. Although the daily apparent root water take agreed well with the daily amount of irrigated water regulated by the cloudbased system, the Penman-Monteith equation sometimes underestimated the daily $E T$. The underestimation might be resulted from the overestimation of the aerodynamic resistance in a greenhouse.
\end{abstract}

Keywords: drip irrigation, penman-monteith equation, potential evapotranspiration, water balance, greenhouse
Volume 2 Issue I - 2018

\author{
Yuki Ito,' Shinsuke Aoki,' Kiyoshi Ozawa, ${ }^{2}$ \\ Hiroshi Takesako, ${ }^{2}$ Eiji Kita, ${ }^{3}$ Muneo Kanno, ${ }^{4}$ \\ Kosuke Noborio ${ }^{5}$ \\ 'Graduate School of Agriculture, Meiji University, Japan \\ ${ }^{2}$ Kurokawa Field Science Center, Meiji University, Japan \\ ${ }^{3}$ Routrek Networks Inc., Japan \\ ${ }^{4} \mathrm{NPO}$ Resurrection of Fukushima, Japan \\ ${ }^{5}$ School of Agriculture, Meiji University, Japan
}

Correspondence: Kosuke Noborio, School of Agriculture, I- I- I Higashimita Tama-ku, Kawasaki, Kanagawa, Japan, Tel +8 I44-934-7I56,Fax +8I-44-934-7I56, Email noboriok@meiji.ac.jp

Received: August 22, 2017| Published: January 31, 2018
Abbreviations: DAT, Day After Transplant; Evapotranspiration, TDR, Time Domain Reflectometry

\section{Introduction}

Due to the accident of the Fukushima Daiichi Nuclear Power Station, top soils in surrounding areas were contaminated with radiocesium. Fertile top soils were stripped off for decontamination and replaced with a less fertile sandy soil with which crop productivity may be decreased. With recent advancements in information, communication, and electronics technologies, it becomes possible for farmers to drastically reduce working time, and to improve crop quality and water use efficiency using a cloud-based decision-making system for crop production. To maintain crop productivity in such a less fertile, we used a cloud-based automatic drip fertigation system, ZeRo.agri (Routrek Networks, Inc., Kawasaki, Japan). Based on remotelymeasured soil water content and environmental conditions inside and outside a greenhouse, an irrigation rate is decided by the cloud-based irrigation system for a target volumetric water content, e.g., the field capacity, to compensate crop's water demand and irrigation conducts every one or two hours in daytime. ${ }^{1}$ evaluated soil water content as root water uptake in vegetated soil where surface irrigation was used. There has been little study on soil water balance accounting for evapotranspiration using surface irrigation. The objective of this work was to investigate water uptake of a bell pepper plant along with evapotranspiration and water balance in the rhizosphere throughout the growing period.

\section{Case presentation}

The experiment was conducted from 7 June to 14 November in 2016 using a side-opened greenhouse (5.5 m wide and $30 \mathrm{~m}$ long) covered with a plastic film. The greenhouse was located in Iitate Village, Fukushima Prefecture in northern Japan. Soil texture was sandy clay loam $(60 \%$ for sand, $25 \%$ for silt, and $15 \%$ for clay in mass basis). Four ridges ( $0.8 \mathrm{~m}$ wide, $30 \mathrm{~m}$ long) were made in parallel to the greenhouse's long direction, and irrigation tubes were laid on the soil surface of each ridge and covered with black plastic mulch. Bell pepper seedlings were transplanted on June 5 by staggering seedlings centered on the irrigation tube with $30 \mathrm{~cm}$ spacing between the seedlings. Drippers with a constant irrigation rate along the irrigation tube were spaced at $20 \mathrm{~cm}$ apart. Liquid nitrogen fertilizer was applied with irrigation water. A certain amount of water according to the intensity of solar irradiance, determined by the cloud-based ZeRo. agri system, to make soil water the field capacity was applied through the drippers from 9 a.m. to 3 p.m. with an hour interval. The dielectric permittivity of soil was measured with 3 -rod-TDR probes $(100 \mathrm{~mm}$ long, $20 \mathrm{~mm}$ spacing with $3.2 \mathrm{~mm}$ dia. rods) ${ }^{2}$ and recorded at a 10 min interval with a CR3000 and TDR100 data logging and measuring system. $^{3}$ Total 12 TDR probes were horizontally installed below a dripper and a bell pepper plant in a two-dimensional array in 3 rows with $10 \mathrm{~cm}$ apart at 5,10,20 and $30 \mathrm{~cm}$ deep from the soil surface. Volumetric water content, $\theta\left(\mathrm{m}^{3} \mathrm{~m}^{-3}\right)$, was estimated as:

$$
\theta=4.53 \times 10^{-2}+2.31 \times 10^{-2} \varepsilon_{b}-4.00 \times 10^{-4} \varepsilon_{b}^{2}
$$

Where $\varepsilon_{b}$ is the dielectric permittivity of bulk soil, the $\theta$ from all the 12 TDR probes at a moment were arithmetically averaged as $\theta_{a}$ for the rhizosphere. The apparent root water uptake by plant, $U$ $\left(\mathrm{mmd}^{-1}\right)$, and daily changes in average volumetric water content, $\Delta \theta_{a}$ $\left(\mathrm{mmd}^{-1}\right)$, are expressed as:

$$
\begin{aligned}
& U=I-\Delta \theta_{a} \\
& \Delta \theta_{a}=\frac{V_{a}\left(\theta_{a}-\theta_{a}^{\prime}\right)}{\Delta t A_{a}}
\end{aligned}
$$

where $I$ is the total amount of irrigated water in a day $\left(\mathrm{mmd}^{-1}\right)$, $V_{a}$ is the effective rhizosphere volume $(300 \mathrm{~mm}$ long $\times 200 \mathrm{~mm}$ wide $\times 350 \mathrm{~mm}$ deep $\left.=2.1 \times 10^{7} \mathrm{~mm}^{3}\right), \theta_{a}$ and $\theta_{a}$ are average volumetric water content $\left(\mathrm{mm}^{3} \mathrm{~mm}^{-3}\right)$ at 5 a.m. on day $i$ and day $i+1$, respectively, $\Delta t$ is the time interval (d) between day $i$ and $i+1$, and $A_{a}$ is the effective rhizosphere surface area $(300 \mathrm{~mm}$ long $\times 200 \mathrm{~mm}$ wide $=$ 
$6.010^{4} \mathrm{~mm}^{2}$ ). Potential evapotranspiration, $E T_{p}$, was estimated with the Penman-Monteith equation ${ }^{3}$ as:

$$
E T_{p}=\frac{\Delta}{\Delta+\gamma} \frac{R_{n}+G}{L}+\frac{\gamma}{\Delta+\gamma}\left(\frac{\rho_{a}^{0}-\rho_{a}}{r_{v a}}\right)
$$

where $\Delta$ is the slope of the temperature $v s$. saturated water vapor concentration curve $\left(\mathrm{kg} \mathrm{m}^{-3} \mathrm{~K}^{-1}\right), R_{n}$ is the net radiation $\left(\mathrm{Wm}^{-2}\right), \mathrm{G}$ is the soil heat flux $\left(\mathrm{Wm}^{-2}\right), \gamma$ is the psychrometric constant $\left(\mathrm{kg} \mathrm{m}^{-3} \mathrm{~K}^{-1}\right), L$ is the latent heat of vaporization $\left(\mathrm{MJ} \mathrm{kg}^{-1}\right), \rho_{a}{ }^{o}$ is the saturated water vapor concentration at air temperature $\left(\mathrm{kg} \mathrm{m}^{-3}\right), \rho_{a}$ is the atmospheric water vapor concentration at air temperature $\left(\mathrm{kgm}^{-3}\right)$, and $r_{v a}$ is the aerodynamic resistance $\left(\mathrm{s} \mathrm{m}^{-1}\right)$ for water vapor transport given by the following equation ${ }^{3}$ :

$$
r_{v a}=\frac{1}{k^{2} \bar{u}} \ln \left(\frac{z-d+z_{H}}{z_{H}}\right) \ln \left(\frac{z-d+z_{M}}{z_{M}}\right)
$$

where $k$ is von Karman's constant $(=0.4), \bar{u}$ is mean wind speed at height $z=2 \mathrm{~m}$ above the ground, assumed to be $0.6 \mathrm{~m} \mathrm{~s}^{-1}$ [4], $d$ is the zero-plane displacement for the surface, and $z_{H}$ and $z_{M}$ are surface roughness parameters for heat and momentum, respectively. In the greenhouse, air temperature, relative humidity, net radiation at $z=2 \mathrm{~m}$ and soil heat flux at $5 \mathrm{~cm}$ below the soil surface were measured and recorded with a CR1000 data logger (Campbell Scientific Inc., Logan, UT, USA) every $10 \mathrm{~min}$. Measurement was lack between DAT=34 and 85 due to mechanical failures. Values of $U$ would be expected to be similar to those of $E T_{p}$ when plants have no water stress, meaning that the proper amount of water is irrigated. In our case, $E T_{p}$ was assumed to be very close to transpiration because the soil surface was covered with a plastic multi so that evaporation from the soil surface would be negligible.

\section{Discussion}

Figure 1 shows comparison of irrigated water, $I$, and apparent root water uptake, $U$, during the growing period. Apparent root water uptake agreed well with irrigated water after DAT $=86$. This result indicates that the ZeRo. agri system determined and controlled the proper amount of irrigated water matched well with water demand of bell pepper plants. Excess water was applied when apparent root water uptake was smaller in the early growing period approximately between DAT $=1$ and 15 . During this period, the Zero, agri system was in an adjusting stage to determine a proper amount of water based on try and error basis. Figure 2 indicates comparison of irrigated water, $I$, and potential evapotranspiration, $E T_{p}$, during the growing period. The $E T_{p}$ tended to underestimate throughout the growing period. The Penman-Monteith eq. might not be used on DAT $<34$ because the surface cover by the bell pepper plants was not enough. In addition, water vapor concentration at $T_{a}$ in the Penman-Monteith eq. might result in underestimating $E T_{p}$ because air temperature distribution over the plant canopy in the greenhouse might not be well established. Fernandez et al. ${ }^{5}$ also reported that the Penman-Monteith equation underestimated measured greenhouse evapotranspiration resulted from large $r_{v a}$ values in Eq. 4 due to low wind velocity $\bar{u}$ in Eq. 5. Since there was a capillary barrier layer, consisting of mostly gravel, below $30 \mathrm{~cm}$ deep, $\theta$ at $30 \mathrm{~cm}$ deep little changed during the growing period so that irrigated water might not infiltrate into the deep layer. The amount of irrigated water controlled by the ZeRo. Agri system agreed well with the amount of water required by the bell pepper plants. Therefore, we concluded that irrigated water was mostly consumed by the bell pepper plants. To improve the fertigation efficiency, further research is needed for fine-tuning the PenmanMonteith equation in a greenhouse and for configuring spatial location of crops and irrigation tubes.

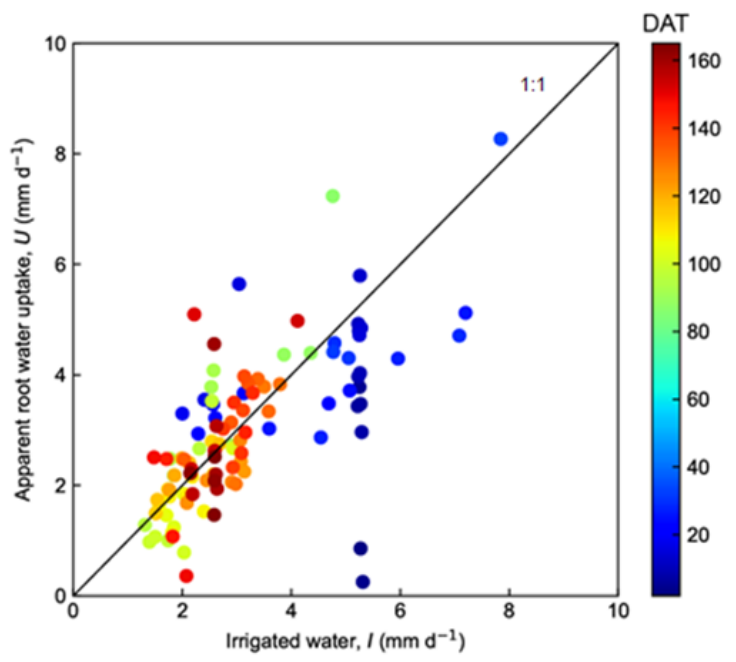

Figure I Comparison of amount of daily irrigated water, I, and apparent root water uptake, $U$.

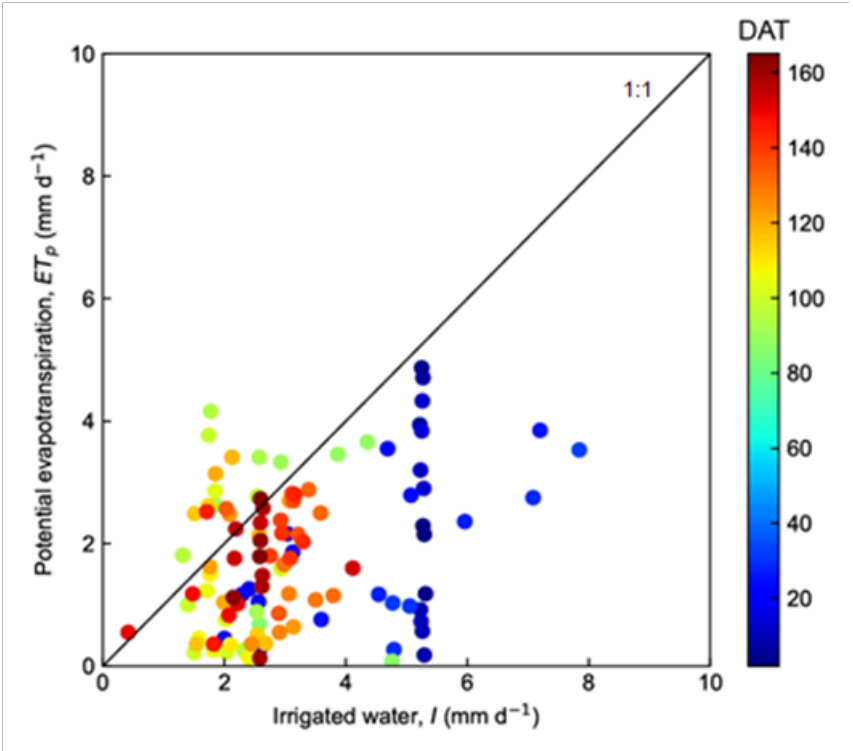

Figure 2 Comparison of amount of daily irrigated water, I, and potential evapotranspiration, ETp.

\section{Acknowledgements}

This research was partly supported by the 2016 Research Grant of the Meiji University Promoting Education and Research Foundation. We are grateful to the members of the NPO Resurrection of Fukushima, Japan for field work.

\section{Conflict of interest}

No financial interest or conflicts of interest exist. 


\section{References}

1. Coelho EF, Dani OR. Root distribution and water uptake patterns of corn under surface and subsurface drip irrigation. Plant and Soil. 1999;206(2):123-136.

2. Noborio K. Measurement of soil water content and electrical conductivity by time domain reflectomery: a review, Computers and Electronics in Agriculture. 2001;31(3):213-237.
3. Campbell GS. Soil physics with BASIC. Elsevier, USA; 1985. p. 1-150.

4. Takeuchi S, Yasuda S, Kawaharada R, et al. Irrigation management of sweet pepper based the measurements of transpiration under greenhouse -studies on the application of the sap flow measurement in irrigation management (I). Trans of JSIDRE. 1998;194:41-49.

5. Fernandez MD, Bonachela S, Orgaz F, et al. Measurement and estimation of plastic greenhouse reference evapotranspiration in a Mediterranean climate. Irrigation Science. 2010;28(6):497-509. 